\title{
BMJ Open A national, cross-sectional survey of children's hospital-based safety resource centres
}

\author{
Sadiqa Kendi, ${ }^{1}$ Mark R Zonfrillo, ${ }^{2,3}$ Karen Seaver Hill, ${ }^{4}$ Kristy B Arbogast, ${ }^{2,3}$ \\ Michael A Gittelman ${ }^{5,6}$
}

To cite: Kendi S, Zonfrillo MR, Seaver Hill K, et al. A national, crosssectional survey of children's hospital-based safety resource centres. BMJ Open 2014:4:e004398.

doi:10.1136/bmjopen-2013004398

- Prepublication history for this paper is available online. To view these files please visit the journal online (http://dx.doi.org/10.1136/ bmjopen-2013-004398)

Received 2 November 2013 Revised 7 February 2014 Accepted 27 February 2014

CrossMark

For numbered affiliations see end of article.

Correspondence to Dr Sadiqa Kendi; skendi@lifespan.org

\section{ABSTRACT}

Objective: To describe the location, staffing, clientele, safety product disbursement patterns, education provided and sustainability of safety resource centres (SRCs) in US children's hospitals.

Methods: A cross-sectional survey was distributed to children's hospital-based SRC directors. Survey categories included: funding sources, customer base, items sold, items given free of charge, education provided and directors' needs.

Results: $32 / 38$ (84.2\%) SRC sites (affiliated with 30 hospitals) completed the survey. SRCs were in many hospital locations including lobby (28.1\%), family resource centres (12.5\%), gift shop/retail space $(18.8 \%)$, mobile units $(18.8 \%)$ and patient clinics $(12.5 \%) .19 \%$ of respondents reported that their SRC was financially self-sustainable. Sales to patients predominated (mean of $44 \%$ ); however, hospital employees made up a mean of $20 \%$ (range $0-60 \%$ ) of sales. $78.1 \%$ of SRCs had products for children with special healthcare needs. Documentation kept at SRC sites included items purchased (96.9\%), items given free of charge $(65.6 \%)$ and customer demographics (50\%). $56.3 \%$ of SRCs provided formal injury prevention education classes. The SRCs' directors' most important needs were finances (46.9\%), staffing $(50 \%)$ and space $(46.9 \%)$. All of the directors were 'somewhat interested' or 'very interested' in each of the following: creation of a common SRC listserv, national SRC data bank and multisite SRC research platform.

Conclusions: SRCs are located in many US children's hospitals, and can be characterised as heterogeneous in location, products sold, data kept and ability to be financially sustained. Further research is needed to determine best practices for SRCs to maximise their impact on injury prevention.

\section{BACKGROUND}

Unintentional injury is the leading cause of morbidity and mortality in children greater than 1 year of age. ${ }^{1}$ It is estimated that 14 million children will sustain an injury which will require medical attention each year, and a significant number of these children will

\section{Strengths and limitations of this study}

- This study is the first to describe the function and variability of children's hospital-based safety resource centres in the USA.

- Safety resource centres are located in many US children's hospitals, and vary in terms of centre settings, products sold, data kept and ability to be financially sustained.

- While the response rate to the survey was high, it is an overall small sample of safety resource centres and does not reflect the activities of those not based in children's hospitals.

have permanent disability. ${ }^{2}$ Several strategies have been used to mitigate these preventable injuries, including education to families about safety practices and use of proven products, development of new safety equipment and legislation to mandate behaviours. Assessment of these various safety practices and policies has been carried out for various states and countries. ${ }^{34}$

There is evidence that the combination of education and increased accessibility of safety equipment increases safety knowledge and behaviour, ultimately making children at lesser risk for future injury. ${ }^{5}{ }^{6}$ One emergency department (ED)-based study revealed that the combination of free home safety equipment and home safety information was effective in improving knowledge and use of home safety devices at a 2-month follow-up. ${ }^{6}$ Another ED study found that the combination of a booster seat with car safety education was more effective than education alone. ${ }^{7}$ Finding innovative ways to provide safety education and offer products free or at reduced costs are the keys to injury prevention.

Children's hospitals that provide medical, surgical and psychiatric care are typically located within urban communities. Because injuries tend to disproportionately affect socioeconomically disadvantaged and non-white 
children who often live in these communities, ${ }^{8}$ these institutions service a demographically diverse group including children at high risk for potential injury. ${ }^{9}$ Gittelman and colleagues $^{5}{ }^{10}$ have previously described the use of a safety resource centre (SRC) located in the ED of a large, tertiary care children's hospital in an urban setting. They found that $97 \%$ of customers contacted in follow-up were still using items they purchased at the SRC, and over one quarter of customers made a change in home safety behaviours after their visit. In total, $75 \%$ of customers who made a purchase did not have previous knowledge of the SRC prior to their visit. ${ }^{10}$

There are currently 38 known SRCs affiliated with 30 children's hospitals. Each SRC is located in its unique setting (eg, ED, gift shop, primary care clinic, etc). The US Children's Hospital Association is a voluntary institutional membership organisation representing 217 children's hospitals in the USA. Conservatively, this membership represents approximately $87 \%$ of all eligible children's hospitals and paediatric units that exist in the Children's Hospital Association, which maintains a comprehensive and current list of these centres and their directors/contacts.

SRCs help provide families with discounted products and enhanced education about safety that many clinicians may not have the time or resources to provide. Despite their recent growth and evidence of success, no study has assessed the state and function of SRCs located in children's hospitals in the USA. The objective of this study was to describe the location, staffing, clientele, safety product disbursement patterns, education provided and sustainability of SRCs in US children's hospitals.

\section{METHODS}

Study design

This was a confidential, cross-sectional survey of children's hospital-based SRCs. The survey was developed by the authors, and edited after receiving feedback from an individual who had experience with SRCs but was not eligible to complete the survey. Consent was implied by completion of the survey. The Children's Hospital of Philadelphia institutional review board reviewed the protocol and deemed this study to be exempt from human subjects research.

\section{Study setting and population}

Directors of children's hospital-based SRCs, or their appropriate managers, were identified by the Children's Hospital Association. Those identified as most knowledgeable about the SRC at each hospital were provided advanced notice of the survey via email notification. The SRC representative was then invited to participate via an email request from the Children's Hospital Association. If a children's hospital was known to have multiple SRCs, the primary contact at that hospital either completed multiple surveys (one for each SRC), or distributed the survey to other colleagues more knowledgeable about their specific SRC.

\section{Study protocol}

The electronic survey was designed, and data collected and managed using Research Electronic Data Capture (REDCap) software, ${ }^{11}$ a secure, web-based application designed to support data collection for research studies. The Children's Hospital Association emailed a cover letter that introduced the study and included a generic web address link to the REDCap questionnaire to all SRC contacts between September and October of 2012 (the survey is available upon request).

After the initial email, three email reminders were sent to non-respondents over a 5-week period. No compensation was offered for participation.

\section{Measurements}

The survey included multiple choice questions with space for additional answers. Survey categories included funding sources, customer base, items sold, items given free of charge, education provided (including 'formal' (ie, targeted, in-person instruction) and 'informal' (ie, written materials and other passive education)), follow-up performed and perceived barriers to managing the SRC.

\section{Data analysis}

Survey results were analysed using Stata (V.10.0, StataCorp, College Station, Texas, USA). Descriptive statistics were used to summarise variables, including proportions, means and medians.

\section{RESULTS}

Thirty-two of 38 sites (84.2\%) affiliated with 30 children's hospitals completed surveys. All sites were established within the past 8 years; the majority (37.5\%) originated in the past 3-4 years. The distribution of the customer base is shown in table 1 .

Table 2 demonstrates the distribution of locations where SRCs operate within the children's hospital setting, and their hours of operation. The SRCs are most commonly located in the hospital lobby $(9,28.1 \%)$ and least commonly found in the ED $(1,3.1 \%)$. Almost all of the sites are open during business hours-31 (96.9\%), with only $14(43.8 \%)$ open in evenings and $12(37.5 \%)$ open on weekends.

\begin{tabular}{lll}
$\begin{array}{l}\text { Table } 1 \\
\text { (N=32) }\end{array}$ & Distribution of safety centre customer base \\
\hline & Median (\%) & IQR \\
\hline Patients & 40 & $22-70$ \\
Community members & 22.5 & $10-60$ \\
Employees & 15 & $2-28$ \\
\hline
\end{tabular}




\begin{tabular}{lcc}
$\begin{array}{l}\text { Table } 2 \\
\text { operation (N=32) }\end{array}$ & N & Per cent \\
\hline SRC characteristics & & \\
\hline SRC location & 9 & 28.1 \\
Hospital lobby & 6 & 18.8 \\
Retail space & 6 & 18.8 \\
Mobile unit & 4 & 12.5 \\
Family centre & 4 & 12.5 \\
Clinic & 2 & 6.2 \\
Free standing & 1 & 3.1 \\
ED & & \\
Weekly hours of operation & 5 & 15.6 \\
$>40$ & 12 & 37.5 \\
30-40 & 8 & 25.0 \\
20-29 & 7 & 21.9 \\
$<20$ &
\end{tabular}

SRCs offer a variety of products and services within children's hospitals. Twenty-three sites $(71.9 \%)$ carry discounted safety products (even further discounted from their base wholesale prices) and 25 sites $(78.1 \%)$ offer products for children with special healthcare needs. Thirty-one sites $(96.9 \%)$ provide informal education in the form of pamphlets or other handouts for equipment sold; however, slightly more than half $(n=18,56.3 \%)$ provide formal injury prevention education and 9 (28.1\%) provide follow-up with families after a purchase is made at the SRC. The purpose of follow-up varies, including assessing customer satisfaction, use of products and disseminating information on product recalls. The majority of sites keep records on items sold (96.9\%) and items given free of charge $(65.6 \%)$; however, only 16 sites $(50.0 \%)$ keep records on customer demographics.

\begin{tabular}{|c|c|c|c|c|}
\hline \multirow[b]{2}{*}{ Products } & \multicolumn{2}{|c|}{$\begin{array}{l}\text { Available } \\
\text { for sale }\end{array}$} & \multicolumn{2}{|c|}{$\begin{array}{l}\text { Available } \\
\text { for free } \\
\text { distribution }\end{array}$} \\
\hline & $\overline{\mathbf{N}}$ & Per cent & $\overline{\mathbf{N}}$ & Per cent \\
\hline Stove shield & 22 & 68.8 & 5 & 15.6 \\
\hline Bicycle helmet & 19 & 59.4 & 13 & 40.6 \\
\hline Cabinet/drawer lock & 19 & 59.4 & 9 & 28.1 \\
\hline Window cord wind-up & 19 & 59.4 & 7 & 21.9 \\
\hline Carbon monoxide detector & 18 & 56.4 & 5 & 15.6 \\
\hline Baby gate & 17 & 53.1 & 7 & 21.9 \\
\hline Combination car seat & 17 & 53.1 & 12 & 37.5 \\
\hline Convertible car seat & 17 & 53.1 & 13 & 40.6 \\
\hline Home child proofing kit & 17 & 53.1 & 13 & 40.6 \\
\hline Backless booster seat & 16 & 50.0 & 12 & 37.5 \\
\hline High back booster seat & 16 & 50.0 & 13 & 40.6 \\
\hline Smoke alarm & 16 & 50.0 & 9 & 28.1 \\
\hline Infant car seat & 14 & 43.1 & 11 & 34.4 \\
\hline Gun lock & 4 & 12.5 & 13 & 40.6 \\
\hline
\end{tabular}

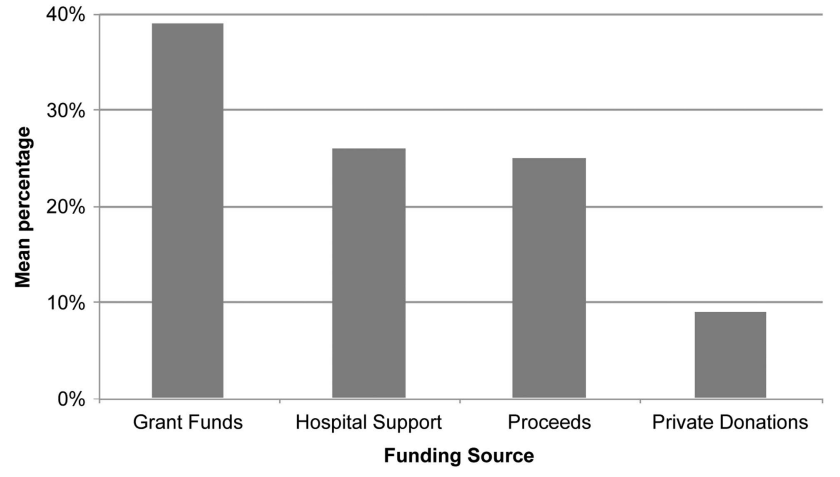

Figure 1 Distribution of funding sources for safety resource centers.

Table 3 lists the products sold and products given free of charge by most SRCs. Some sites had identical products available for sale and available for free distribution.

SRC staffing also varies, with 0-6 paid staff and 0-9+ unpaid volunteers. Nineteen sites $(59.4 \%)$ require child passenger safety (CPS) certification, and $20(62.5 \%)$ require other informal training for their paid staff. Six sites $(18.8 \%)$ require other types of formal training for staff, and two sites $(6.3 \%)$ require no training. Fewer sites require training for their volunteer staff: $3(9.4 \%)$ CPS certification and formal curricular training, 9 (28.1\%) informal training and $3(9.4 \%)$ no training.

Sites are primarily funded by grants and hospital support (figure 1). Twelve sites $(37.5 \%)$ report an annual gross income between US $\$ 5000$ and US $\$ 10000$, with the remainder reporting an income range of US $\$ 10$ 000-US $\$ 50000$. Only $18.8 \%$ of SRCs identified as being self-sustainable. Respondents reported barriers and needs in management of the SRC, with 16 sites $(50.0 \%)$ identifying staffing issues, $15(46.9 \%)$ lack of funds, $15(46.9 \%)$ storage space and $12(37.5 \%)$ lack of time as significant barriers. All respondents were interested in future collaboration through using a listserv to share information electronically with other SRCs, a national data bank of all SRCs, as well as collaborative research.

\section{DISCUSSION}

This is the first study to describe the state and function of US children's hospital-based SRCs. These results show that SRCs vary widely in the way they function, their clientele, and in the services and products provided. SRCs are traditionally defined as centres which provide discounted or free injury prevention equipment in addition to injury prevention education to families. ${ }^{10}$ However, this study found that only half of SRCs offer formal, hands-on injury prevention education. Prior work has shown that the combination of equipment with formal education is the best strategy for increasing proper use of injury prevention equipment. ${ }^{6} 7$ The current practices of SRCs assessed in our study included the distribution of written education materials with 
many purchases. Future studies should determine, identify and assess best practices for SRC activities.

Prior descriptions of SRCs have focused on single institutions, without a comparison across various locations or a description of the customers served. ${ }^{10}{ }^{12}$ This study has identified that the customer demographics across SRCs vary widely, and has confirmed findings identified in a previous analysis that employees comprise a significant percentage of customers in some sites. ${ }^{13}$

The barriers to managing SRCs identified consistently by sites included staffing issues, lack of storage space and lack of time, all of which are influenced by funding. This is supported by the fact that only $18.8 \%$ of SRCs identified as self-sustainable, an issue which has been previously discussed in the literature. ${ }^{5}$ This study did not explicitly ask about the business model for the SRCs or ask respondents to indicate if the centre was established with the intention of being self-sustaining. However, many SRC directors felt that the best way to become truly self-sustainable would be to increase equipment prices, which contrasts with the goal of making injury prevention equipment more accessible to lower income, high-risk families. One possible strategy to increase the sustainability of SRCs is to leverage the fact that many customers are hospital employees. Previous studies in the business literature have shown that employee wellness programmes are up to six times as profitable as the initial investment in such programmes. ${ }^{14} \mathrm{~A}$ novel funding and advertising idea for SRCs is to market themselves as part of employee wellness programmes, as the benefit of injury prevention to the children of employees may provide significant benefits as do other aspects of the programme. Income derived from purchases by employees may help offset costs to provide injury prevention equipment to other more disadvantaged groups. Studies have shown that injuries tend to disproportionately affect socioeconomically disadvantaged and nonwhite children, possibly related to lack of culturally appropriate education, language barriers and socioeconomic status. ${ }^{8} 15$ The urban communities surrounding many children's hospitals are those in which many of these families live. The presence of SRCs in these communities, supported by their local children's hospital, is one important way to reduce the significant morbidity and mortality from unintentional injury.

This study did have some limitations. The survey was limited to children's hospital SRCs identified by the Children's Hospital Association, and therefore may not be generalisable to SRCs that are not affiliated with children's hospitals. The survey was completed by the director of each SRC, and therefore based on their recollection and understanding of the function of the site, possibly introducing recall bias. Although the survey did include a few open-ended questions, it was not predominately qualitative, and fine details may not have been identified. Additionally, the relative benefits of the various SRC interventions and the customers' use of the safety products were not measured. Finally, the survey was confidential but not anonymous, which may have biased responses.

\section{CONCLUSIONS}

Children's hospital-based SRCs vary widely in the way they function, their clientele, and in the services and products provided. They have similar challenges, most of which are related to funding and sustainability. The issues of sustainability may be addressed by increased financial support for SRCs by the children's hospitals which host them, especially due to the significant benefit to the children in the communities the hospitals serve, as well as the children of hospital employees. Future collaborative research will help to confirm best practices for location, staffing and funding at sites, as well as ways to improve the income and sustainability of SRCs.

\section{Author affiliations}

${ }^{1}$ Department of Emergency Medicine, The Alpert Medical School of Brown University, Providence, Rhode Island, USA

${ }^{2}$ Division of Emergency Medicine, Center for Injury Research and Prevention, The Children's Hospital of Philadelphia, Philadelphia, Pennsylvania, USA ${ }^{3}$ Department of Pediatrics, Perelman School of Medicine, University of Pennsylvania, Philadelphia, Pennsylvania, USA

${ }^{4}$ Children's Hospital Association, Alexandria, Virginia, USA

${ }^{5}$ Department of Clinical Pediatrics, University of Cincinnati School of Medicine, Cincinnati, Ohio, USA

${ }^{6}$ Division of Emergency Medicine and Comprehensive Children's Injury Center, Cincinnati Children's Hospital, Cincinnati, Ohio, USA

Acknowledgements The authors would like to thank the safety resource centre directors and administrators who participated in the study.

Contributors SK, MRZ, KSH, KBA and MAG designed the research, conducted the research, reviewed and approved the final version of the manuscript. SK analysed the data, drafted the manuscript and had primary responsibility for the final content.

Funding This study was funded by the Nicholas Crognale Chair for Emergency Medicine at The Children's Hospital of Philadelphia.

\section{Competing interests None.}

Ethics approval Exempt from review by The Children's Hospital of Philadelphia institutional review board.

Provenance and peer review Not commissioned; externally peer reviewed.

Data sharing statement No additional data are available.

Open Access This is an Open Access article distributed in accordance with the Creative Commons Attribution Non Commercial (CC BY-NC 3.0) license, which permits others to distribute, remix, adapt, build upon this work noncommercially, and license their derivative works on different terms, provided the original work is properly cited and the use is non-commercial. See: http:// creativecommons.org/licenses/by-nc/3.0/

\section{REFERENCES}

1. Centers for Disease Control and Prevention (CDC). Web-based Injury Statistics Query and Reporting System (WISQARS). http:// www.cdc.gov/injury/wisqars (accessed 1 Jul 2012).

2. Janssens L, Gorter JW, Ketelaar M, et al. Long-term health condition in major pediatric trauma: a pilot study. $J$ Pediatr Surg 2009;44:1591-600.

3. Centers for Disease Control and Prevention. Prevention Status Report. Available at http://www.cdc.gov/stltpublichealth/psr (accessed 31 Jan 2014). 
4. European Child Safety Alliance. Child Safety Report Cards. http:// www.childsafetyeurope.org/reportcards/index.html (accessed 31 Jan 2013).

5. Gittelman MA, Pomerantz WJ. Starting a pediatric emergency department safety resource center. Pediatr Ann 2009;38:149-55.

6. Posner JC, Hawkins LA, Garcia-Espana F, et al. A randomized, clinical trial of a home safety intervention based in an emergency department setting. Pediatrics 2004;113:1603-8.

7. Gittelman MA, Pomerantz WJ, Laurence S. An emergency department intervention to increase booster seat use for lower socioeconomic families. Acad Emerg Med 2006;13:396-400.

8. Brown RL. Epidemiology of injury and the impact of health disparities. Curr Opin Pediatr 2010;22:321-5.

9. Children's Hospital Association. All children need children's hospitals. 3rd edn. 2007. http://www.childrenshospitals.net (accessed 15 Nov 2013).

10. Gittelman MA, Pomerantz WJ, Frey LK. Use of a safety resource center in a pediatric emergency department. Pediatr Emerg Care 2009;25:429-33.
11. Harris PA, Taylor R, Thielke R, et al. Research electronic data capture (REDCap) - a metadata-driven methodology and workflow process for providing translational research informatics support. $J$ Biomed Inform 2009;42:377-81.

12. Gielen AC, McKenzie LB, McDonald EM, et al. Using a computer kiosk to promote child safety: results of a randomized, controlled trial in an urban pediatric emergency department. Pediatrics 2007;120: 330-9.

13. Edmonds S, Arbogast KB, Duchossois GP, et al. Usage characteristics of a children's hospital safety center. Pediatric Academic Societies' Annual Meeting. Washington, DC, 2013.

14. Berry LL, Mirabito AM, Baun WB. What's the hard return on employee wellness programs? Harv Bus Rev 2010;88: 104-12, 142.

15. McDonald EM, Solomon B, Shields W, et al. Evaluation of kiosk-based tailoring to promote household safety behaviors in an urban pediatric primary care practice. Patient Educ Couns 2005;58:168-81. 